\title{
The modal shift to sustainable railway transport in Serbia
}

\author{
Zdenka Popović ${ }^{1, *}$, Luka Lazarević ${ }^{1}$, Mirjana Vukićević $^{1}$, Milica Vilotijević ${ }^{1}$, Nikola \\ Mirković $^{1}$ \\ ${ }^{1}$ University of Belgrade, Bulevar Kralja Aleksandra, 73, Belgrade, 11000, Serbia
}

\begin{abstract}
This paper deals with actual European "modal shift to rail transport" concept and related environmental issues and experience in the Republic of Serbia. The planned increase in volume of railway transport and planned railway electrification should reduce air pollution in Serbia, particularly in the urban environment. On the other hand, achieving this goal would lead to the increase in noise level in the urban environment and environmental issues in the region of thermal power plants, which are the main sources of electricity in Serbia. This paper suggests concrete measures to reduce the railway carbon footprint and noise level during the planning, design and service life of railway infrastructure.
\end{abstract}

\section{Introduction}

Sustainable transport policy in Serbia defines development courses for the utilization of energy from renewable and new sources and energy efficiency improvement. Therefore, railway electrification has to be based on domestic resources (primarily coal) and renewable energy sources. It is clear that electric locomotives with regenerative braking system contribute to the reduction of total energy consumption and carbon footprint. On the other hand, diesel locomotives, which emit combustion products, significantly contribute to air pollution, especially in the vicinity of marshalling yards. It is necessary to control air pollution by reduction of fuel consumption, growth of energy efficiency, and use of alternative fuels.

Nevertheless, railway electrification does not necessarily contribute to the environmental protection. In Serbia, more than $90 \%$ of the annual coal production is used for electricity production, and about $62 \%$ of electricity is produced in lignite-fired thermal power plants (TPPs). The electricity production in TPPs contributes to air pollution, as well as land contamination in the area of TPPs. It is important to state that about 300 million tons of fly ash and slag are disposed on the landfills in the vicinity of TPPs, taking up to 1.600 hectares of fertile land [1].

This paper suggests concrete measures to reduce the railway carbon footprint using fly ash for construction of the railway embankment. Furthermore, the measures to reduce railway noise in an urban environment were discussed.

\footnotetext{
${ }^{*}$ Corresponding author: zdenka@grf.bg.ac.rs
} 


\section{The measures to reduce the railway carbon footprint in Serbia}

In general, the railway carbon footprint is lower compared to other modes of transport, as shown in Figure 1. Unfortunately, the carbon footprint of Serbian railways is higher compared to other railways because the electricity is produced mainly in TPPs.

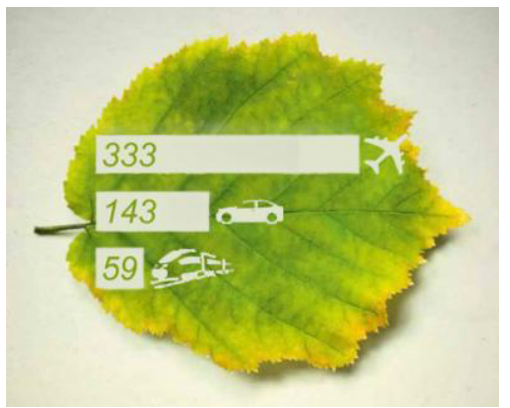

Fig. 1. Impact of different transport modes on the climate expressed as $\mathrm{CO}_{2}$ emission (values are in grams per passenger-km $[2,3])$.

Large quantities of fly ash and slag (about 7 million tons/year of fly ash and slag) devastate the environment close to TPPs in Serbia (Figure 2). This is a long-term problem because the lignite will remain the essential resource for electricity production in the future. Despite the fact that lignite is the most cost effective resource for electricity production worldwide, it is the largest domestic resource which enables the energy independence.
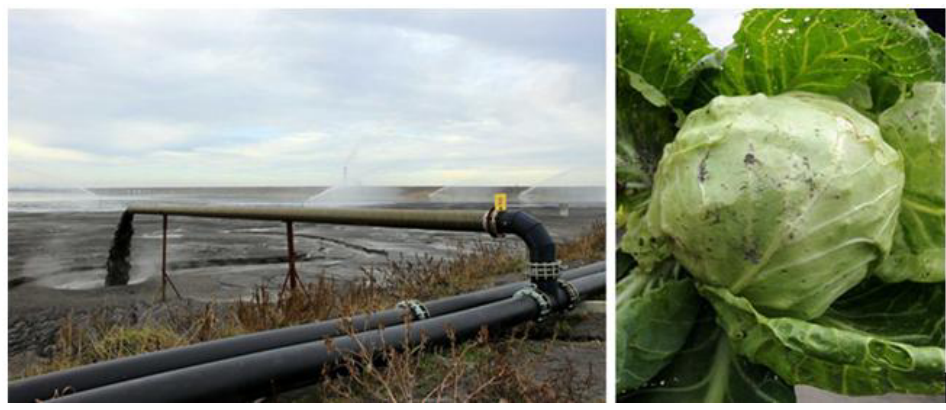

Fig. 2. Related environmental issues: devastation of the environment (left) and food contamination (right) in Serbia (photos taken in Obrenovac, 2016).

Furthermore, the utilisation of lignite for electricity production significantly increases the carbon footprint in Serbia. In order to reduce the total railway carbon footprint, the researches of the possibility of fly ash utilisation for the construction of railway embankment are still in progress. Fortunately, the preliminary results of geotechnical laboratory testing showed that investigated fly ash and slag (produced in TPPs in Serbia) could be suitable for utilisation in the railway infrastructure (Figure 3) [1-4]. The fly ash from Serbian power plants has pozzolanic properties but, because of low concentration of calcium compounds (less than $10 \% \mathrm{CaO}$ ), it is devoid of self-cementing characteristics. Because of this it is usually necessary to add binders (such as cement or lime) to fly ash in order to improve its mechanical properties [1,4]. Mechanical properties (CBR, shear strength parameters, compressibility modulus) of all tested samples of fly ash with the addition of binders meet European technical requirements.

Before the practical utilisation of fly ash for the construction of the railway substructure, the risk of leaching of hazardous substances was investigated in the laboratory $[5,6]$. The 
leaching tests results of fly ash from TPP "Morava" showed that the addition of lime could control the risk of leaching of hazardous substances (e.g. arsenic and selenium), which could jeopardize the environment (soil, water and ultimately human health).

The responsibility of the Infrastructure Management is great due to environmental risks. Therefore it is necessary to measure the leaching from the railway embankment at the test section.

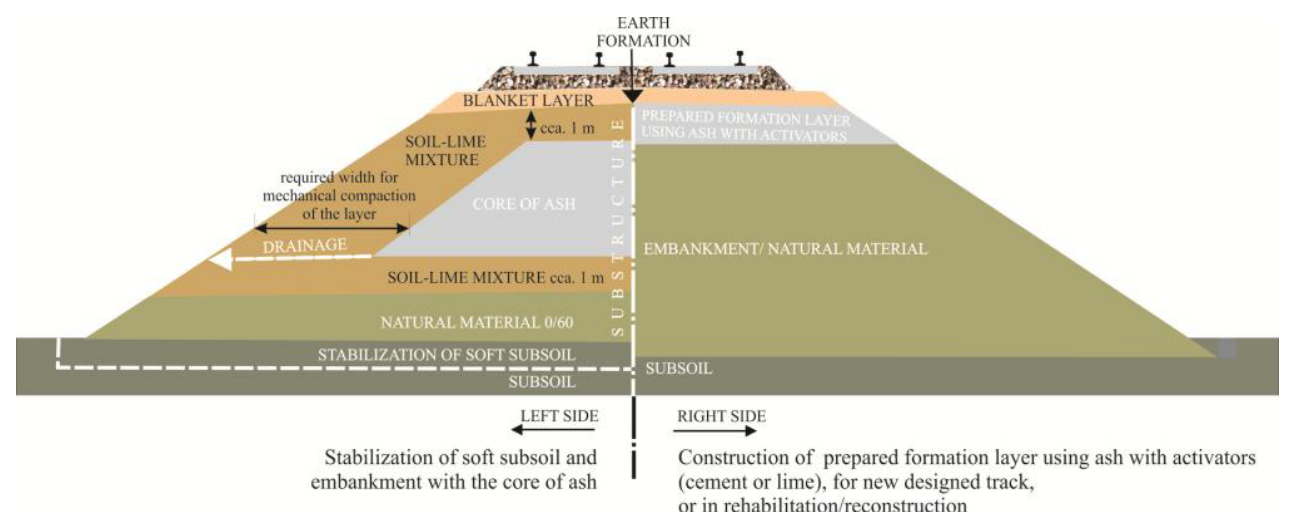

Fig. 3. Possible utilisation of fly ash for the construction of embankments [1].

\section{The measures to reduce the railway carbon footprint in Serbia}

The planned increase in railway transport in Serbia would increase the noise level from railway traffic (intensive freight transport particularly during the night). Therefore, it is very important to analyse and define necessary activities and decisions for noise managing during the process of design, construction and maintenance of railway infrastructure.

\subsection{Planning and design}

Earlier studies assigned by the European Commission have shown that rolling freight wagons were the most important source of railway noise. Since many freight trains operate at night, the produced noise and vibrations are even more harmful in the urban environment. The very complex environmental impact of railway transport in the urban environment is primarily defined in the planning and design processes of the railway infrastructure. Therefore, it is very important to plan the railway infrastructure for freight transport far away from the urban zone (e.g. in the industrial zone). Furthermore, design of the passenger railway transport subsystem including passenger terminals and stations in the urban environment (if possible below ground surface) increases the competitiveness of rail transport compared to other modes of transport. Figure 4 shows the new design of Belgrade railway junction, based on the separation of infrastructure for passenger and freight. 


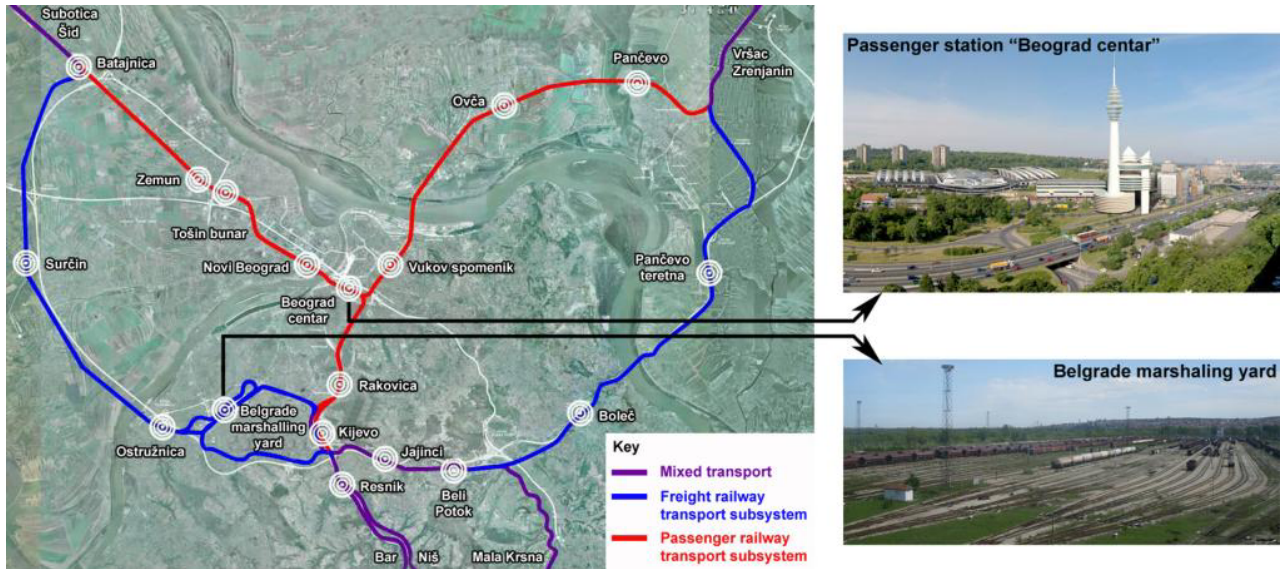

Fig. 4. Design of Belgrade railway junction (construction in progress).

The modern rail terminals and effective access roads should have an optimal position and rational use of expensive land in the urban environment. They have to provide an efficient interchange between different modes of transportation, good connection with the main city roads and reduction of road transport in the urban environment. In addition, rail terminal design should improve the urban ambient and provide maximum comfort for citizens [7].

Modern railway passenger stations and terminals use the vertical plane for content organisation (e.g. high speed or conventional railway, regional railway, metro), which provides independent corridors for different modes of transportation, without conflicting intersections [8]. This distribution of contents implies fast interchange between different modes of transportation. The noisiest mode of transportation should be placed in the lowest subterranean level.

Other very important design measures are railway line routing, alignment parameters, type of the superstructure and substructure. From the aspect of environmental protection, the best railway routing solution is the infrastructure below ground surface in the downtown area (tunnel or deep cut). Otherwise, "above ground" position of railway infrastructure in the urban environment is the worst solution that requires the rail-road crossing at the different levels (special issues of noise and vibration from rail bridges) and application of secondary noise protection (e.g. noise protection barriers and windows).

The expected construction and maintenance costs, the volume and types of construction and maintenance activities, as well as ecological impact on the environment are highly dependent on the chosen railway alignment elements (e.g. curve radius, superelevation and transition curve design, longitudinal slope, inclination) and designed type of superstructure (ballasted or ballastless track) and substructure (bridge, tunnel, embankment, cut).

In the urban environment, it is possible to use superstructure with ballasted or ballastless track (slab track). However, the slab track has significant advantages in the urban environment. The main ecological advantages of ballasted track are better acoustic properties - the noise level of slab track is $5 \mathrm{~dB}$ higher than noise level of ballasted track with wooden sleepers [9]. Other advantages of the ballasted track are lower price (compared to price of slab track), and possibility of engaging the domestic (Serbian) suppliers and professional construction and maintenance operators.

The most important ecological disadvantage of the ballasted track in the urban environment is an increase in noise and vibration emission due to the track geometry deterioration [10]. This process is followed by the reduction of drive comfort and requires correction of track geometry by using mechanized maintenance (which produces noise, 
vibration and dust). In the urban environment, design of ballasted track is extremely limited and slab track is better solution due to the minimal maintenance costs, as well as long service life [11]. The special designs have been developed in order to provide environmental suitability of slab track, such as: embedded rail systems with continuous rail support, grass cover in "green track", mass-spring systems, special "silent" rail fastening systems (Figure 5), prefabricated elements for noise absorption in track etc.
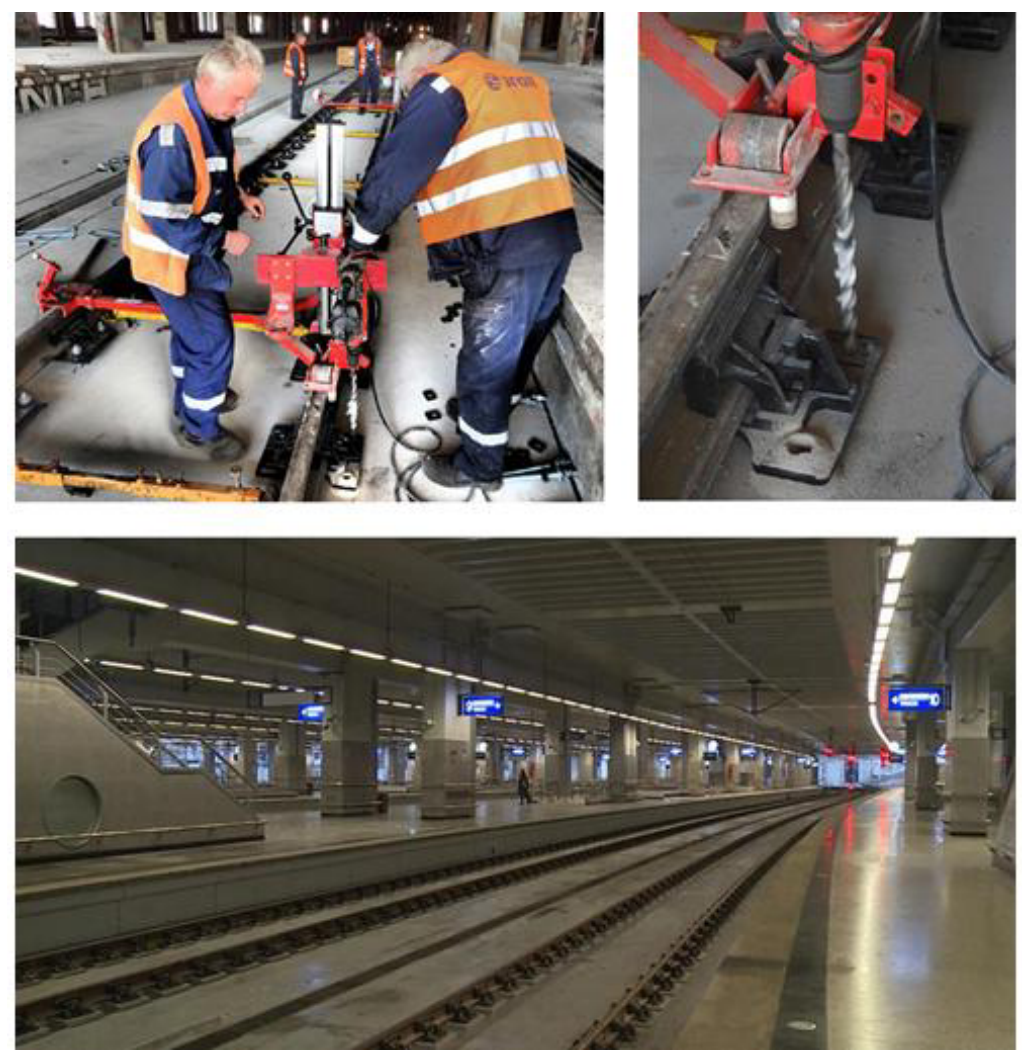

Fig. 5. Installation of Vanguard - Pandrol fastening system (up) (photos taken in "Beograd Centar" station, 2015) and slab track in new passenger station in Belgrade (down) (photo taken in "Beograd Centar" station, 2017).

\subsection{Construction and maintenance}

Technology and organization of construction and maintenance have to meet the requirements for environmental protection.

As indicated above, the basic disadvantage of ballasted track is an unavoidable track geometry deterioration, which requires intensive maintenance [10]. Operations of maintenance mechanization can be highly noisy (e.g. tamping, dynamic stabilising, ballast compaction, ballast replacement/cleaning) and with significant GHG emission (dieselpowered mechanization). An additional difficulty is restricted work space for operation of maintenance mechanization in the urban environment (heavy city traffic, lots of installations etc.). Planning of maintenance operations is limited by the permissible noise level during night time.

The first step in effective control of noise is identification of the dominant source. Previous noise analyses have identified the wheel-rail contact as a major problem in the 
urban environment $[12,13]$. Therefore, it is important to maintain contact surface of both the wheel and rail head.

The simple examples in Figure 6 confirm the imperative to maintain both the wheel and the rail throughout the life cycle. Figure 6 (a) shows the equal "A" noise levels of both the wheel and the rail. The total noise level can be determined using Equation 1.

$$
10 \log \left(10^{A / 10}+10^{A / 10}\right)=A+10 \log 2 \approx A+3 d B
$$

When the noise emitted by one element is decreased by $10 \mathrm{~dB}$ (e.g. either after rail grinding or after wheel grinding, Figure 6(b)), total noise level decreases insignificantly for human ear, as indicated by Equation 2.

$$
(A+3)-10 \log \left(10^{A / 10}+10^{(A-10) / 10}\right)=A+3-A-10 \log 11 / 10 \approx 2.6 d B
$$

This means that the maintenance of only the one element (either wheel or rail) does not make sense.

When the noise levels emitted by both elements are decreased by $10 \mathrm{~dB}$ (e.g. after grinding both the rail and the wheel, Figure 6(c)), total noise level decreases by:

$$
\begin{aligned}
& (A+10 \log 2)-10 \log \left(10^{(A-10) / 10}+10^{(A-10) / 10}\right)= \\
& =A+10 \log 2-A-10 \log 2-10 \log 10=10 \mathrm{~dB}
\end{aligned}
$$

This means that both the wheel and the rail should be maintained and proves that the cooperation between Infrastructure Managers and Transport Operators is necessary in the maintenance process. Furthermore, implementation of the legal principle "polluter pays" has great significance for environmental protection.

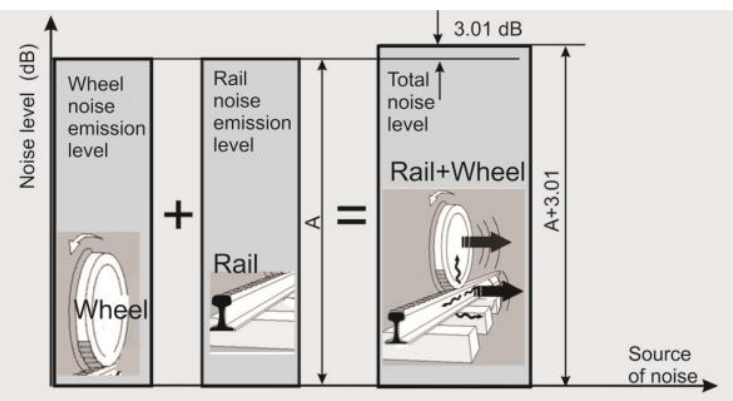

a) Total noise level at equal rail and wheel noise emission levels

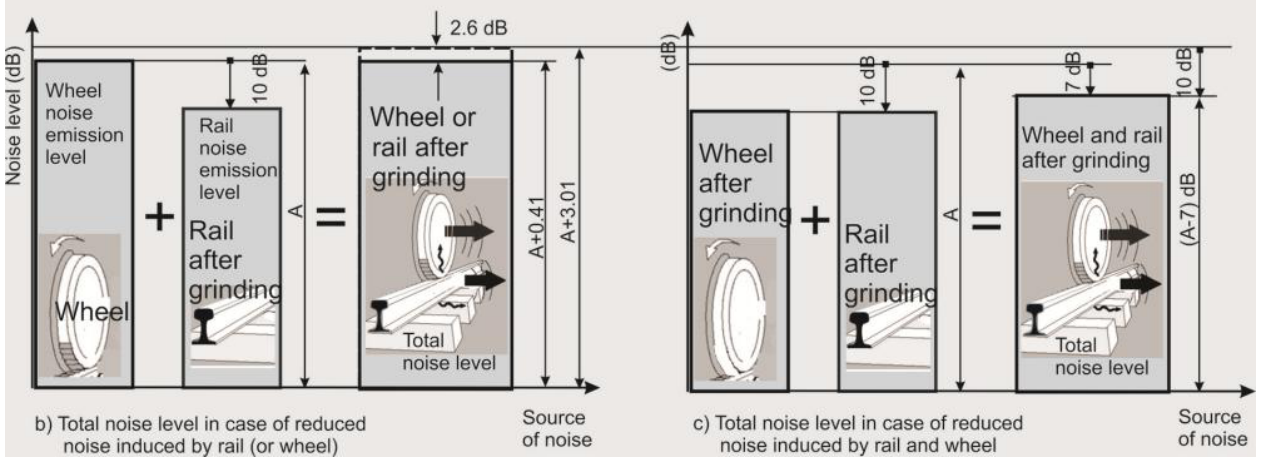

Fig. 6. Total rail/wheel noise depending on the maintenance activities. 
Corrugation on running surface of rail head is phenomenon which occurs in both ballasted and slab track [14-16]. Experience shows that corrugation of the rail, which is continually supported, slowly progresses comparing to the discretely supported rail. Therefore, rail corrugation cannot be inhibited, but it`s occurrence could be delayed.

Reprofiling of the rail head (action that is undertaken to modify the longitudinal or transverse profile of a rail in track) should be applied in order to eliminate running surface corrugation. Modern strategy of rail grinding includes preventive grinding, as well as cyclic and corrective grinding/milling activities. The combined rail milling/grinding technology (Figure 7) achieves a greater effect and excludes any risk of fire compared to the rail grinding technology. Application of rail milling/grinding technology reduces the time necessary for reprofiling of rails (one working pass) and it can be applied in the sensitive environment.

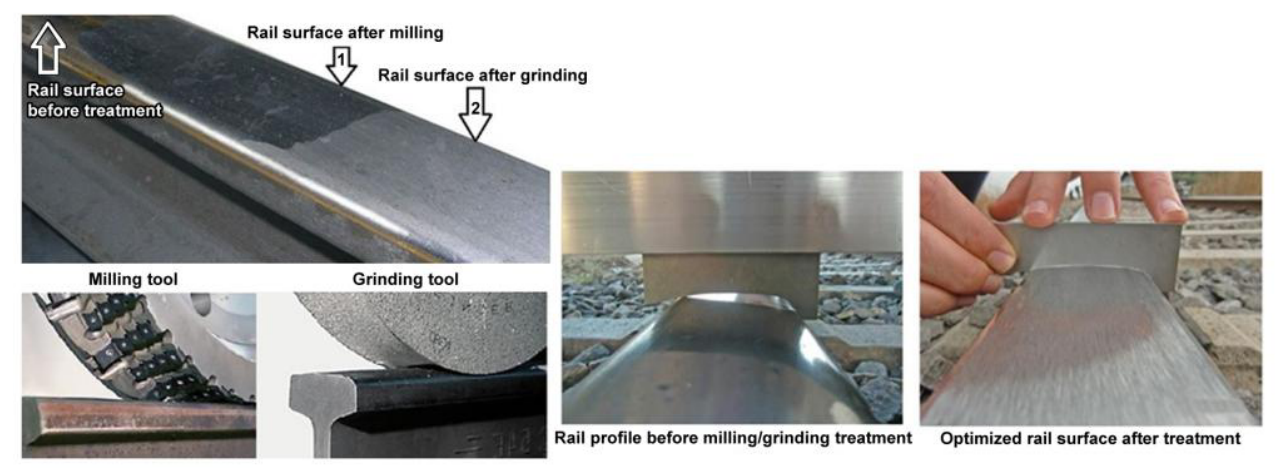

Fig. 7. Rail surface before and after milling/grinding technology according to [17].

At the same time, grinding is an effective measure against the development of rolling contact fatigue (RCF) defects (squat, head checking and belgrospi, Figure 8) [18, 19, 20] which could endanger the safety in case of improper maintenance. Unfortunately, grinding effect is not permanent, since corrugation and RCF rail defects will reoccur. 


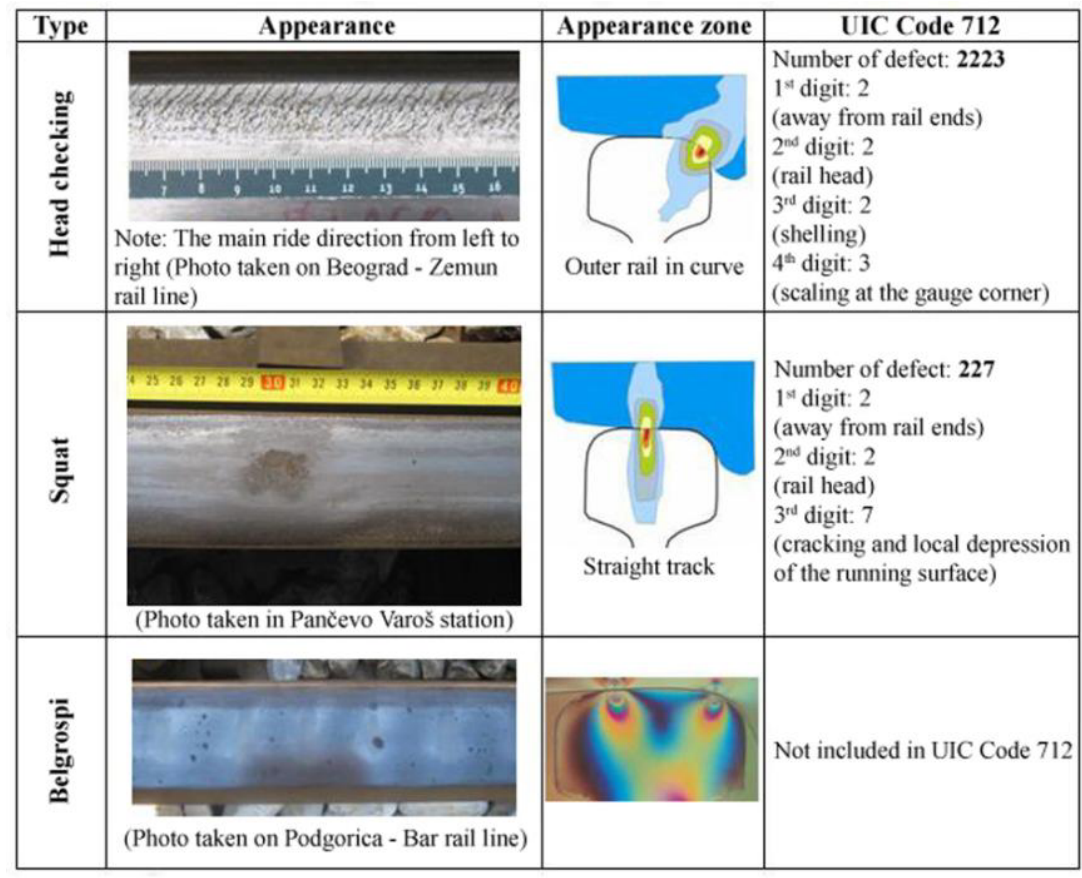

Fig. 8. Types, appearance zones and marking of RCF defects.

An effective grinding strategy is based on the effective rail inspection and continuous noise monitoring. The main goal of rail milling/grinding strategy is reduction of total track and vehicle maintenance costs [21]. The additional benefits are stable ride, extended service life of rails and track, as well as the reduction of vibration and noise.

Research presented in [22] discussed the "integrated approach" for the ballasted track maintenance and it recommended synchronization of cyclic grinding with tamping cycle, renewal of rails/sleepers, and ballast replacement/cleaning cycle. The integrated maintenance approach (replacement of concrete sleepers and rails at the same time) should reduce total maintenance costs of infrastructure and environmental impact (Figure 9).

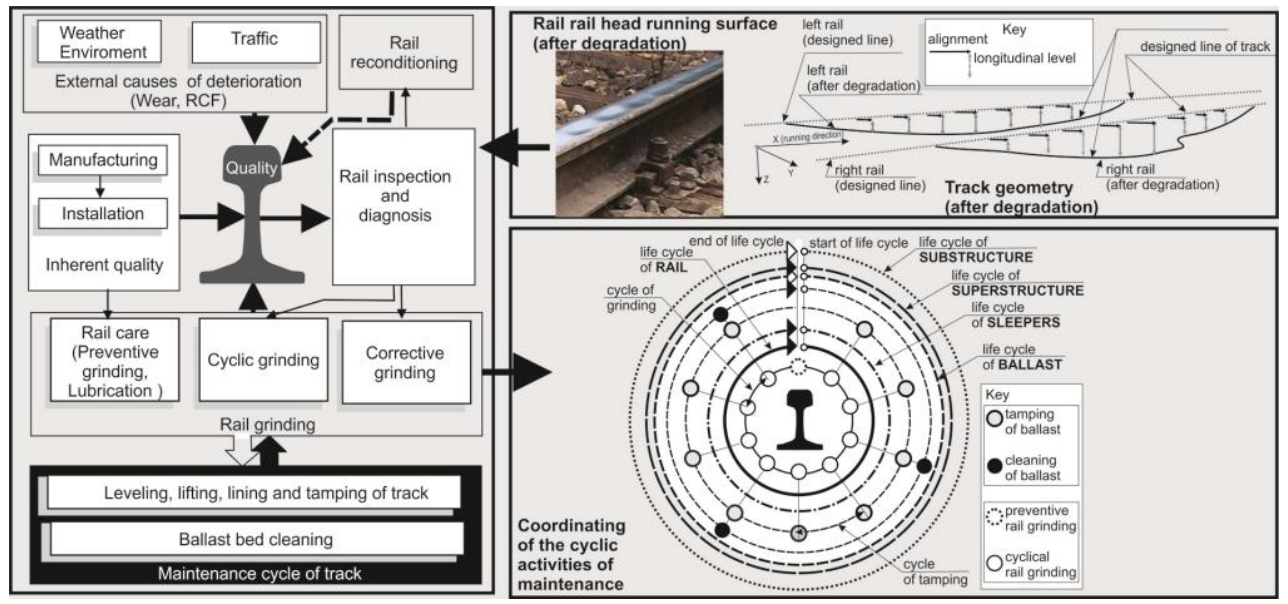

Fig. 9. The principle of integrated maintenance. 


\section{Conclusions}

The authors suggest that the compound environmental impact of the railway infrastructure cannot be considered separately. The environmental requirements must be solved on the basis of global analysis in the planning and design processes of the railway infrastructure including construction and maintenance requirements in the urban areas. The paper points out the specific construction and maintenance conditions in the urban areas which influence the design of infrastructure (e.g. slab track design, continuous welded rails, large curves to control of squeal noise, application of milling/grinding technology, etc.). The authors suggest that the environmental impact of the railway infrastructure is complex and that the most important decisions are made in the planning and design processes of the railway infrastructure. In addition, the paper emphasizes the importance of cooperation between Infrastructure Managers and Transport Operators during the maintenance of both infrastructure and vehicles.

The design solution of railway junction and the main passenger station in Belgrade is an example of a good relationship with the urban environment and poor utilisation of capacities. This example demonstrates that the implementation of sustainable transport policy is a crucial framework for successful realization of the "modal shift to rail" concept (the competitiveness of railway with other transport modes based on "user pays - polluter pays" principles and effective connections with other modes of transport - access roads, interchanges, integrated timetables, etc.).

The environmental consequences of poorly designed infrastructure are difficult to correct during service life of railway infrastructure. Dealing with environmental consequences makes higher costs and less effect compared to dealing with the environmental requirements in planning, design, construction and maintenance processes.

\section{Acknowledgements}

This work was supported by the Ministry of Education, Science and Technological Development of the Republic of Serbia through the research project "Research of technicaltechnological, staff and organisational capacity of Serbian Railways, from the viewpoint of current and future European Union requirements" (No. 36012).

\section{References}

1. M. Vukićević, Z. Popović, J. Despotović, L. Lazarević, Transport 1, 10 (2016)

2. https://germanwatch.org/klak/flug04.pdf

3. M. Vilotijević, Izgradnja 69(3-4), 106-116 (2015)

4. M. Vukićević, V. Pujević, M. Marjanović, S. Jocković, S. Maraš-Dragojević, Građevinar 67(8), 761-770 (2015)

5. B. Kidric, Kontrola radioaktivnosti u životnoj i radnoj okolini termoelektrana Nikola Tesla (Institute of Nuclear Sciences, Belgrade, 1999)

6. M.K. Tiwari, S. Bajpai, U.K. Dewangan, R.K. Tamrakar, Journal of Radiation Research and Applied Sciences 8(4), 523-537 (2015)

7. K. Stevanović, Z. Popović, Sustainable Urban Development - Terminal Novi Belgrad (International Conference, Belgrade, 2013)

8. M. Stevanović, K.Stevanović, Gradevinar 66(8), 739-747 (2014) 
9. http://www.dlr.de/ts/Portaldata/16/Resources/dokumente/vk/Vortrag_Buchmann_05 1006.pdf

10. L. Lazarević, Assessment of Track Geometry Quality Using Fractal Analysis of Measured Data (University of Belgrade, Belgrade, 2016)

11. E. Darr, W. Fiebig, Eurailpress 1, 45 (2006)

12. Z. Popović, L. Puzavac, L. Lazarević, Ecologica 63(18), 467-471 (2011)

13. WG Railway Noise of the European Commission (2003)

14. E. Hohnecker, Schienenfahrweg für das 21 Jahrhundert (Final report, Karlsruhe, 2004)

15. UIC Code 712: 2002

16. UIC Code 725: 2007

17. http://www.linsinger.com/de/produkte/schienentechnik/schienenfraes-technologie/218-21.htm\#

18. Z. Popović, V. Radović, Građevinar 65(3), 251-259 (2013)

19. Z. Popović, L. Brajović, L. Lazarević, L. Milosavljević, Technical Gazette 21(1), 147-153 (2014)

20. Z. Popović, L. Lazarević, L. Brajović, M. Vilotijević, Procedia Engineering 117, 596-608 (2015)

21. Z. Popović, V. Radović, L. Lazarević, V. Vukadinović, G. Tepić, Metallurgy 52(4), 537-540 (2013)

22. Z. Popović, L. Lazarević, Lj. Brajović, P. Gladović, Metallurgy 53(4), 721-724 (2014) 